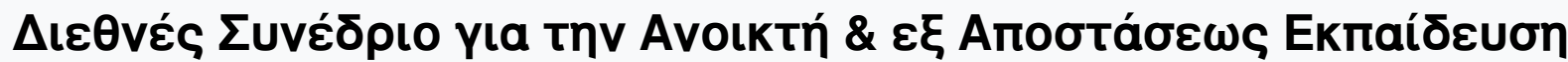

Tóp. 10, Ap. 3A (2019)

\section{ПPAKTIKA}

$10^{C}$ EYNEAPIO TIA THN ANCIKTH \& E AחCETALERI EKMAIAEYLH

를

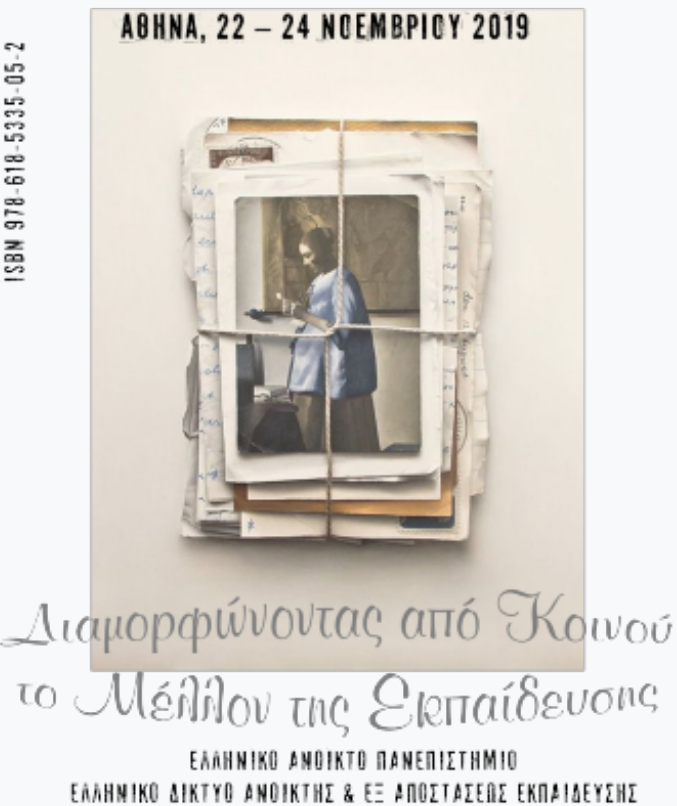

A Proposed Quality Assurance Procedure for Distance Learning Programs: Design, Development and Implementation.

Nikleia Eteokleous, Raphaela Neophytou

doi: $10.12681 /$ icodl.2436

\section{TOMOL 3, MEPOEA}




\title{
A Proposed Quality Assurance Procedure for Distance Learning Programs: Design, Development and Implementation
}

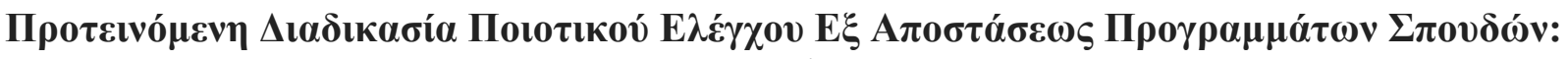

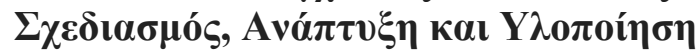

\author{
Nikleia Eteokleous

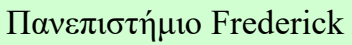 \\ mail@nikleia.net
}

\author{
Raphaela Neophytou

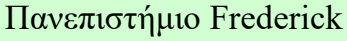 \\ raphaelaneophytou@gmail.com
}

\begin{abstract}
The explosive growth and the rapid diffusion of the Internet, created new approaches to teaching and learning specifically in higher education. The interest in the development and use of distance learning in higher education has been steadily increasing and the past four decades. The Distance Learning Committee of Frederick University, has developed a procedure for Internal Quality Assurance Procedure for the distance learning programs as part of the university's implementation of strategic planning in providing quality distance learning education and updating continuously the distance learning program of studies. The goal of this research was to implement and evaluate the internal quality assurance procedure as well as to identify and discuss whether the courses (design, delivery, assessment, interaction etc) are aligned to the philosophy, the pedagogical framework and the guidelines of DL operations provided by the Distance Learning Committee to DL stakeholders.
\end{abstract}

Key words: distance learning programs, quality assurance procedure, higher education

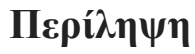

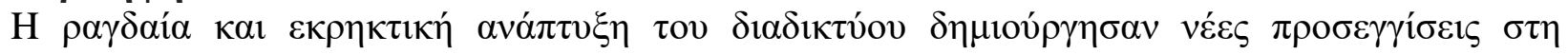

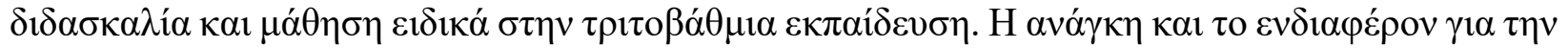

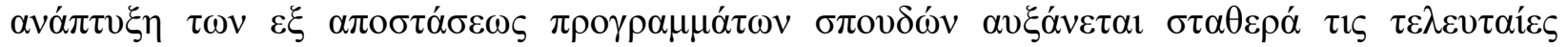

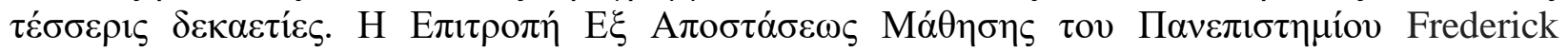

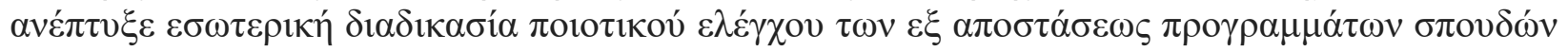

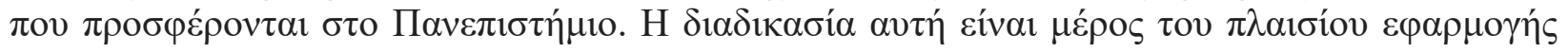

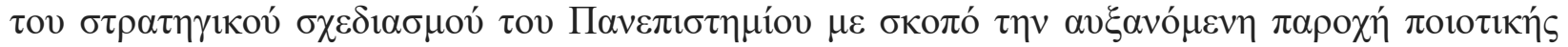

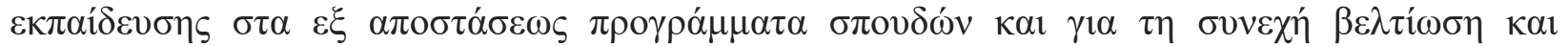

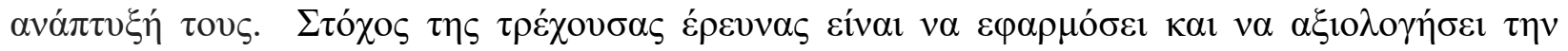

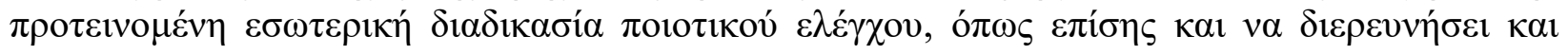

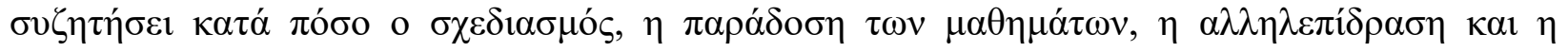
$\alpha \xi$ ıо

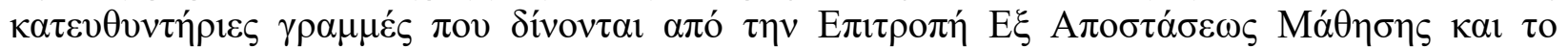

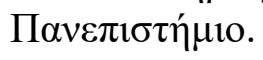




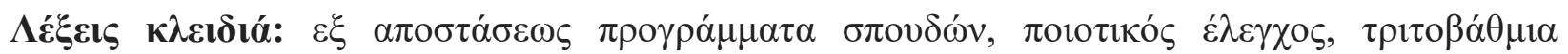
$\varepsilon \kappa \pi \alpha i ́ \delta \varepsilon v \sigma \eta$

\section{Introduction}

The explosive growth and the rapid diffusion of the Internet, created new approaches to teaching and learning specifically in higher education (Crosta, 2004; Hewitt, 1998, Martin, Budhrani, Kumar, \& Ritzhaupt, 2019). The interest in the development and use of distance learning in higher education has been steadily increasing and the past four decades. As reported by Seaman (2017) approximately 6 million of students attended at least one online learning course in 2015. Consequently, the past twenty years the number of higher education institutions around the globe offering distance learning degrees have been significantly increased.

Distance Learning is a system and a process that connects learners and instructors at remote locations. It can be described by the phrase "anytime, anywhere learning" (Berge, 1999; Tianguang Gao, \& Lehman, 2003). Online courses as a medium to implement distance learning; has been a pervasive new channel for education that makes it more accessible, more appealing to students, as well as enabling new ways of learning (Tianguang Gao \& Lehman, 2003). Online courses require different teaching and learning models, and design principles to be implemented.

Frederick University established in 2007 after a long and successful presence in Cypriot higher education. It is one of the first 3 private universities granted a permanent license of operation in 2012. Since its operation, a remarkable growth has been achieved in student and faculty population and research output. Frederick University seized the opportunity granted by the ECPU in June 2012 to introduce new programs of study using the distance learning mode of delivery. Offering distance learning programs was seen both as an opportunity and as a challenge. An opportunity, because given the established demand for such programs, and additionally, the ability to reach students that would be otherwise impossible, provided growth opportunities for the University. This was also seen as a challenge because for Frederick University, as with all programs, achieving and maintaining quality was of paramount importance (Eteokleous, Louca, Charalampous, Valanides, Hadjiconstantinou, Kyriacou, \& Tsorakis, 2013). Within the Internal Quality Assurance System, an additional internal quality evaluation procedure is developed and implemented for the Distance Learning Programs of Study. The Internal Quality Committee in collaboration with the Distance Learning Committee (DLC) developed an evaluation quality process to ensure that specific standards are met regarding the operation of the DL programs of study. The evaluation takes place based on quality indicators derived from the Pedagogical Framework that underpins the design, development and delivery of the Distance Learning Programs of Study. The procedure identifies gaps and good practices in order for suggestions for improvements and requested actions to be communicated via personalized reports to the DL instructors and DL coordinators. The Distance Learning Committee (DLC) and the Open and Distance Learning Center (ODCL) oversee and monitor the quality evaluation process for the DL programs of study. The internal quality reporting process is obtained through the following data collection instruments 1) Evaluation rubric - courses observation, 2) Learning Management System Data analytics, ad 3) the Student Course Evaluation questionnaire.

Frederick University is one of the 21 Universities in Europe to receive E-xcellence label for Associates in Quality. After six year of operation Frederick University was awarded the excellence label by the European Association of Distance Teaching Universities (EADTU), 
Europe's leading institutional association in online, open and flexible Learning. By achieving the E-xcellence Associates in Quality label, Frederick University demonstrates that it offers quality controlled e-learning and keeps up to date with the latest developments. Furthermore, that it uses the E-xcellence instrument for benchmarked self-assessment on e-learning and take measures of improvement accordingly. By becoming an E-xcellence Associate in Quality, Frederick University is now part of a network of universities with opportunities to meet virtually with peers and experts in the field of e-learning. Frederick University will have access to the expertise of other universities and share its own expertise with them in a virtual community. The University is recognized as operating in a continuous process of improving its e-learning performance. The evaluation and the e-xcellence label was based on the following six pillars: 1)Strategic Management, 2) Program Design and Development, 3) Course Design and Development, 4) Course delivery, 5) Staff Support, and 6) Student Support.

With E-xcellence, EADTU is leading a European movement of universities that follow new developments and innovations in e-learning. The E-xcellence Associates are focusing on the improvement of four priority elements of progressive higher education: Accessibility, Flexibility, Interactiveness and Personalisation. So far 21 E-xcellence awards have been handed out to faculties and universities all over Europe.

Firstly, the context of the study is described where the Distance Learning Strategy, the Pedagogical Framework, and the Internal Quality Assurance procedure. The second pat of the paper presents the implementation of the internal quality assurance procedure for the the distance learning programs of study. Therefore, it is described how the basic evaluation takes places in two phases collecting qualitative data. Subsequently, the quantitative data collection process is presented where data is collected from two main sources: the questionnaire completed by the student and data collected via the learning management platform. Finally, research methodology and initial results are given.

\section{Main Aim and Research Objectives}

After 6 years of Distance Learning Programs implementation, the Distance Learning Committee (DLC) put in place the proposed quality assurance plan. The current study, as part of a greater research project, aims to implement and evaluate the proposed internal quality assurance procedure as well as evaluate DL operations and specifically DL courses development and delivery. More specifically, the overall project examines the alignment of the courses (design, delivery, assessment, educational material, interaction etc) to the philosophy, the pedagogical framework and the guidelines of distance learning operations provided by the DLC to related stakeholders (instructors and teaching assistants). It also aims to provide recommendations to further improve the evaluation process in order to meet both the needs of the institution, and to be able to effectively support the DL programs, thus the DL coordinators, instructors, and students.

The current research study aims to address the following research questions:

- To identify the current deviations and their degree: minor or major,

- To examine the reasons of deviations existence and how to address these deviations,

- To identify good practices and their degree: minor or major.

The part of the study that is presented and discussed in this paper focuses on describing and explaining the internal quality assurance procedure and provides initial results in regards to the first research question. 


\section{The Context}

\section{Distance Learning Strategy}

Frederick University has incorporated the development and expansion of its Distance Learning (DL) programs of study within the pillars of its core aims, thus assuring relevant drive and direction, for inclusion of DL within the University. Specifically, within the University's strategic plan clear aspects relating to the operation and continuous development of DL and its programs of study exist. Based on this, specific targets and goals have been set in the University's action plan and these have been communicated to the relevant bodies, for implementation. According to the University's organizational structure, each body has clear responsibilities and authorities, which relate to and support the provision of DL programs of study.

Furthermore, the University implements a Quality Management System, which includes internal regulations, policies and procedures and thus ensures continuous quality improvement. Frederick University's Distance Learning Policy (DLP) defines the framework for the DL operation, including its conformity to legal and ethical requirements. The DLP was developed by the DLC and approved by the Senate. Local guidelines regarding provision of DL programs, are enforced and monitored by the regulatory authority, the C.Y.Q.A.A. (The Cyprus Agency of Quality Assurance and Accreditation for Higher Education) and define specific requirements prior to registering students; this includes the framework for evaluation and accreditation of programs of study by an external team of experts, where one member of the evaluation team is a DL expert.

\section{The Pedagogical Framework for Online Courses Design developed by the Distance Leanring Committee}

The Pedagogical Framework (PF) and its elements mainly define the evaluation parameters of the suggested internal quality assurance procedure. The PF serves as the backbone of the design of new programs of study and intended for online learning delivery. Furthermore, the PF explains the manner in which various stakeholders are involved in this endeavour interacted in order to successfully accomplish design, implement and deliver online learning programs of study. The proposed framework is based on research evidence and contemporary theoretical approaches to online learning in higher education and capitalises on the expertise gained by academics and instructional designers from participating in research and educational projects related to distance and open learning. The PF was built upon various Online Pedagogical models such as the Five stage model of E-learning by Salmon (2000, 2004), the Community of Inquiry Model by Garrison, Anderson and Archer (2000, 2007), and Shea and Bidjerano (2010) and the ExConTra by Makrakis and Costoulas-Makrakis (2012) and other research findings (i.e. Stephenson, 2001; Salmon, 2007; Shea, \& Bidjerano, 2010; Watts, 2010).

The PF was developed after resolving the following crucial issues: 1) the location of potential students (local, and/or European, and/or international students), 2) international trends and research developments regarding the mode of delivery of distance learning programs and 3) the requirements set by the regulatory authority in terms of accreditation of distance learning programs and the recognitions of degrees awarded from such programs. 
The PF provides an academically sound framework within which programs and content is to be developed. It describes the adopted mechanisms of achieving learning via distance and what is expected to be provided and finally it serves as guideline for course design. The PF consists of the following three pillars, grouped in Learning Activities and Assessment Activities:

- Directed Learning Online (Learning Activities)

- Mandatory Content

- Supplementary Content

- Dynamic Online Interaction (Learning Activities)

- Assessment Activities: Formative/Continuous, Summative and Self-assessment (See Diagram 1: Pedagogical Framework Diagram) (Eteokleous et al, 2013).

\section{Description of the Internal Quality Assurance Procedure}

The DLC has developed a procedure for internal Quality Assurance for the DL programs as part of the university's implementation of strategic planning in providing quality distance learning education and continuous updating of the DL programs of studies. The DLC recognizes the need of quality assurance and continuous improvement of quality and the effective operation of the program of studies.

The developed procedure is in line with international practices, policies and research results as well as with the guidelines and instructions of the regulatory authority, C.Y.Q.A.A. The Quality Assurance procedure that is part of this procedure refers to academic issues and does not cover/include administrative support processes. The quality assurance procedure described is part of the Quality Assurance Policy and System of the University, which is developed and implemented by the Internal Quality Committee. The Distance Learning Committee closely collaborates with the Internal Quality Committee in regards to the following:

- new programs of study/courses design,

- existing programs of study/ courses review and update,

- implementing the quality assurance procedure and ensuring that the necessary actions are taken.

The Quality Assurance Procedure aims to examine, evaluate and identify the levels of compliance or of no relevance to the teaching of the distance learning programs as defined by the Pedagogical framework regulating the DL at Frederick University, the duties form of the distance learning programs instructors, as well as the procedures that must be kept in accordance within the operation of the University. The evaluation also aims at carrying out formative measures and taking timely actions in matters of non-compliance, as well as to identify and then to disseminate good practices and examples. Finally, it seeks to take steps towards recognizing and rewarding good practices and examples. Examples of non-compliance and good practices are reported and explained during the DL Instructors training sessions, as well as disseminated through the DL Instructors' Portal and the DL Induction Course. Additionally, good practices are also identified through the research performed by the Open and Distance Learning Center (ODLC). The DLC in collaboration with the ODLC schedules every semester, introductory training for the new DL instructors. Follow up trainings are scheduled when new developments, processes or policies relating to DL delivery are in place. Finally, trainings are also implemented upon request.

The identification of gaps (non-compliances) and good practices facilitate the review, update and revision of the DL programs operation and specifically course development, design and delivery. 
Based on the above, this procedure intends in strengthening the mechanisms of continuous improvement of the quality of teaching, as well as in developing a culture of teaching quality in the distance learning programs. This will greatly assist in the further evolvement of the University's prestige and improve its competitive position in relation to other congener Universities locally and abroad in the distance learning education. In particular, the University's procedure concerning the non-compliance review in the DL programs intends to:

- systematically enhance and improve the infrastructure and the procedures of online teaching,

- improve the online teaching and learning environments,

- develop online learning environments that meet European and international standards and specifications,

- update systematically the teaching methods and resources, and implement innovative teaching methods,

- upgrade the technical and online infrastructure to support instructors,

- upgrade the websites of the online courses and specifically the content and educational material of the online courses,

- reinforce the full use and integration of the Information and Communication Technologies in educational procedures,

- improve the distance learning programs on a regular basis.

At Frederick University the Information Systems Office manages, supports and develops an information technology system, which constitutes the principal database. Furthermore, the elearning platform Moodle, is exploited for the development and delivery of the distance learning courses. Both the information technology system FRE and the electronic platform (LMS) are the main sources of information/data collection for collecting quantitative and qualitative data required for the quality assurance and evaluation procedure.

\section{Implementation of the Internal Quality Assurance Procedure for Distance Learning Programs of Study}

\section{Qualitative Data Collection - Basic Quality Evaluation}

The basic quality evaluation is conducted in two phases and it is mainly based on qualitative data. The $1^{\text {st }}$ phase of the quality assurance procedure includes the observation and evaluation of courses based on a number of parameters and the $2^{\text {nd }}$ phase of the basic quality assurance procedure includes the development of reports for each program of study and each DL instructor. The two phases are explained below in detail.

$1^{\text {st }}$ phase - Every two years, an evaluation is carried out for all courses taught in the current year within the fall and spring semesters. As aforementioned, the evaluation is based on specific criteria/parameters resulting from the Pedagogical framework and the course design requirements as well as the responsibilities of the distance learning instructors and specifically on the basis of what is expected in a distance learning course (overall evaluation as a course and weekly basis evaluation). The DL instructors' responsibilities are described in the Study Guide for Distance Learning Instructors as well as in the contract given to the instructors to sign at the beginning of each semester. The evaluation takes place by the ODCL officers in collaboration with the DLU officers under the guidelines and directions of the DLC. 
The evaluation process is described below. If the instructor has included what is requested then the symbol " $\sqrt{ }$ " is given, if not, the symbol "X" is given. Due to the fact that this way of assessment can be considered absolute, there is a column where comments and clarifications are provided when is deemed necessary. These criteria are assessed based on the expected elements/parameters' integration in the course and not based on the content of the course.

- Firstly, week 0 is assessed which differs from the other weeks and includes: welcoming message and/ or video by the instructor, course outline/syllabus, getting to know each other discussion forum (optional), discussion forum of general enquiries/questions (forum for discussion, questions and communication - it runs throughout the semester), information sources and necessary references, the digitized book of the course/ readings of the course the $1^{\text {st }}$ teleconferencing session and the recorded link of the $1^{\text {st }}$ teleconferencing session.

- Then, the remaining weeks are assessed (all in the same way). The parameters checked in each week are as follows: dates, title of the week/unit, keywords (optional), description of topics (word/ pdf file) and learning objectives of the week/unit, readings (e.g. digital book(s), e-books, articles, newsletters, case studies, etc), educational material (e.g. simple, narrated and annotated presentations, interactive presentations, and documents, screen casting documents, podcasting documents), dynamic interactive online activities via collaboration and content development tools (e.g. discussion forums, blogs and wikis, google documents, videoconferencing, audio conferencing and text conferencing) and assessment methods (self-assessment and/or graded exercises/ assignments, online quizzes and midterms).

- After the evaluating all the weeks/units based on the parameters, an overall evaluation and a numerical grade is provided. For example, the narrated presentations, the annotated presentations, or the teleconferencing sessions are not obligatory for every week but all instructors are required to develop a specific number for each presentation type and organize a specific number of teleconferencing sessions, depending on the course duration. $2^{\text {the }}$ phase - For the implementation of the second phase the data collected during the first phase are required. The ODLC officers under the guidelines of the DLC prepare evaluation reports for each program of study and for each instructor taking into consideration the evaluation for all of the courses taught. The report of each instructor consists of 2 parts:

- Firstly, there is a table which is divided in two parts. One part of the table provides information regarding the degree of consistency for week1 and the second part of the table provides information regarding the degree of consistency for the rest of the weeks.

- The marking given for each parameter is categorized into 3 levels: a) Full deviation (0 points), b) Partial deviation (1/2 points) and c) No deviation (1 point). At the end of each table the overall degree of consistency is calculated for each instructor.

- In addition to the marking, comments and suggestions are given in order to better guide and help the instructors understand and realize where to focus and what is expected to be accomplished. The comments are as follows:

○ No Deviation - and/or guidelines/suggestions for improvement: In this category suggestions/guidelines/directions for improvement are given to instructors who have no particular deviations. Therefore, good practices and examples to follow are identified and collected in order to be presented at the DL Instructors' Portal and DL Induction Course.

- Minor Deviations: Important parameters which are missing from the course and should be integrated by the instructor are presented in this category. They may not 
fall under the category of major deviations but this does not mean that they are optional or not-important. Suggestions for improvement and/or recommendations of closing the gaps (additions of missing elements) are given.

- Major deviations: This category includes important elements which are missing and are significant to be present in a distance learning course, hence the instructors are expected to treat these as urgent and significant to be addressed before the commencement of the new semester. For example, this category includes, specific number of teleconferencing sessions and the recorded ones, duration of teleconferencing sessions, dynamic online interactive activities (e.g. tools employed, methods), variety of simple, annotated, narrated and interactive presentations. Suggestions for improvement and/or recommendations of closing the gaps (additions of missing elements) are given.

The report of each instructor is communicated to the coordinator of the program as well as to the instructor. Meetings take place with the coordinator of each program as well as with the instructors. The Distance Learning Committee is also informed about the evaluation reports. The ODLC organizes meetings (face to face and/or online) with the DL coordinators and DL instructors to guide and support them through the process of enhancing, changing and improving their content. In cases of major deviations an evaluation takes place by the end of the following semester in order to ensure that the suggestions have been addressed, changers were made and deviations were decreased and/or eliminated. In the cases where major deviations still exist a second report is developed by the ODLC and the DLC. The program coordinator is informed and specific actions are expected to be decided. In cases where simple deviations exist, the evaluation takes place after one academic year.

\section{Qualitative Data Collection - Comprehensive check / Check of specific parameters}

At the beginning of each semester, and specifically during the $3^{\text {rd }}$ week of the courses a comprehensive check on specific parameters takes place. For example, the ODCL teams conducts a quick check on: week 0 (mentioned before), the content of week 1,2 and 3 (mentioned before), student enrollment, access to the course, student activity.

\section{Quantitative data Collection (information system)}

Besides the qualitative data, quantitative data are also collected by the ODLC from two main sources: 1) questionnaires completed by the students by end of the semester for each coursr and 2) data analytics and information collected via the Learning Management System (LMS-Moodle). Questionnaires completed by students - The questionnaire has 16 questions and is divided in two parts. The first part includes statements related to the course content and delivery and the second part of the questionnaire includes questions regarding the instructors. The results of the completed questionnaires are posted on Extranet (online internal management system) where the instructors have access. The DL coordinators also have access to the questionnaire results. The DL coordinator of each program is expected to inform/give feedback to the Distance Learning Committee at the end of each semester regarding the academic course/instructor that need close attention. Taking into account that the students use a Likert scale 1-5, the coordinators are expected to inform the DLC when an instructor overall evaluation 3/5 and less. Moreover, the DL coordinators are expected to inform the DLC when a DL instructor gets excellent rates and can be considered as a 
good practice and an example. As aforementioned good practices are presented at the DL Instructors' Portal and DL Induction Course.

Data Collection from the Learning Management System (LMS-Moodle) (Data Analytics) Quantitative data are also collected every semester from the Learning Management System (Moodle). In particular, the DLC gets information from the platform in regards to the following:

- Activity and student participation in the platform (access)

- Number, type and methods of assessment / assignments (e.g. self-assessment, online quizzes)

- Feedback on the assignments

- Number of self-assessment exercises

- Number of collaboration tools employed (e.g. discussion forums, wikis, chat rooms)

- Use of other technological tools for collaboration and group work purposes

- Student participation in dynamic interactive online activities (e.g. discussion forums and student posts)

- Exploitation of technological platform tools

- Employment of content development tools

- Number, duration and content of teleconferencing sessions

- Student participation in teleconferencing sessions

- Use of alternative materials (printed material, digital material, links, videos, pictures, charts, presentations - variety of presentations)

- Interactive presentations (e.g. presentations in the form of SCORM)

\section{Research Methodology \& Sample}

Qualitative methodology was employed in order to analyze the data collected from the courses. During the Spring Semester of 2018, data the DL programs of study were collected and analyzed. More specifically, quality assurance procedure was implemented for the DL programs of study (100 DL courses and 90 DL instructors) offered by three schools of Frederick University during Spring Semester 2018. As shown the table below the following number of courses per School were evaluated: 6 courses offered by the School of Business and Law programs, 1 course offered by the School of Health Sciences and 4 courses offered by the School of Education and Social Sciences.

\section{Initial Results}

The deviations are grouped in two categories: minor and major, without meaning that minor deviations are not important and should not be taken into consideration. The deviations presented at Table 2, do not exist all together in a particular course, however they were identified as a synopsis of the deviations revealed to exist at the DL courses under evaluation.

The simple deviations category includes elements mainly relayed to the lesson's structure and elements missing. At the beginning of the course the DL instructor is expected to welcome his/her students employing a combination of the following approaches: text, video, teleconferencing. This considers to be extremely necessary due to the absence of physical contact between the instructors and the students. The aforementioned was absent from lots of courses since the instructors preferred to introduce themselves only through text. Additionally, in many courses the instructors did not include the discussion forum discussion forum of general enquiries/questions (forum for discussion, questions and communication - it runs throughout the semester). It is important for 
both the students and the instructor to have a floor to express any concerns and questions regarding the course. The goal of the particular forum is mainly supportive/ administrative and it is not related to the learning goals of the course (e.g. content discussion). In all of the courses the syllabus was uploaded which is extremely important for the students to be aware of the content of the course, its main goal and objectives, the assessment, the communication and interaction methods and activities, the bibliography and of course their responsibilities. In some courses, each week was not consistently structured in order for the students to easily navigate within the course and identify the elements needed, i.e. content, readings, quizzes, assignments, deadlines, etc. In some courses the title, course summary content and objectives were missing making it difficult for students to follow the course.

The major deviations category includes elements related to the content, the educational material, the instructor(s) and students' interaction and the delivery of the course. It has been revealed that in few cases not all necessary reading sources were available. The absence of Open Educational Resources (OERs) and the use of social media tools was also revealed. Additionally, the lack of presentations' variety (simple, narrated, annotated and interactive) was identified. Additionally, another deviation revealed that considers to be extremely important is the interaction between the instructor and the students, among the students and the between the student and the content. Some instructors did not integrate the aforementioned in their courses to the desired degree and approach. The DLC gives great emphasis on interaction, communication, collaboration among all partners involved. One of the three main pillars of the Pedagogical Framework is Dynamic Online Interaction, where it includes student-to-student and student-to-teacher interaction and collaboration and encourage student active engagement and participation. Additionally, student to content interaction is achieved through SCORM presentations and virtual simulations. The ODLC, which is responsible in helping educators to develop and revise the educational materials, is in the process of working along with the instructors to develop more advanced SCORM presentations as well as identifying appropriate and relevant virtual simulation environments to be integrated within the DL courses. Finally, the student-to-content interaction is also promoted through online quizzes. The ODLC team is in the process of developing more online quizzes to be included within the courses for self-evaluation purposes.

In very few cases the requested evaluation assignments were missing as well as the self-assessment methods, i.e. quizzes, reflective journals. The last major deviation is related to the number, the duration and content of the teleconferencing sessions. In all of the course there were teleconferencing sessions organized and delivered, however deviations on the number, the duration and the approach were revealed. There were cases where the instructors did not organize the expected number of teleconferencing sessions, or the content of the sessions were not related to content delivery but to addressing students' questions only.

\section{Concluding Remarks}

More data is in the process to be analyzed in order to evaluate the quality of the DL programs of study, such as DL students' questionnaires. The results of the questionnaires will be compared and contrasted to the aforementioned results. The upcoming results are expected to provide more information in regards to the demographics, educational background, beliefs, attitudes of the instructors which revealed to have no deviations, minor and major deviations, attempting to also identify the reasons of the deviations existence. Identifying the reasons of the deviations existence would help the DLC to appropriately define actions and policies to address the gaps. Additionally, 
identifying and revealing good practices would help to boost DL instructors' confidence and provide live examples to follow.

It seems that the DL instructors need continues support and guidance. The role of the DLC and the ODLC is extremely important. They need to provide guidelines and support to be able to effectively and successfully deliver DL courses in regards to content development and delivery, and to students', instructors' and content engagement and interaction. It seems that help, motivation and guidance is extremely necessary and important in regards to achieving active engagement and interaction through various activities (discussion forums, blogs, wikis, online quizzes, and reflective journals, narrated and annotated presentations). Student-to-student and student-to-teacher interaction and collaboration and encourage student active engagement and participation should be further promoted. For example, student to content interaction is achieved through the development of interactive presentations and student-to-content interaction is also promoted through virtual simulations and online quizzes. DL instructors need guidance, help and training to achieve the aforementioned. Most importantly, closed collaboration among DL instructors and the ODLC deems to be extremely necessary.

\section{References}

Berge L.Z., \& Collins, M.P. (1995). Computer mediated communication and the online classroom. eds. Distance learning: Volume III. Cresskill, NJ: Hampton Press.

Crosta,. L. 2004. Beyond the use of new technologies in adult distance courses: an ethical approach. International Journal on E-Learning, Vol. 3, No. 1, pp 48-61.

Eteokleous, N., Louca, P., Charalampous, C., Valanides, N., Hadjiconstantinou, E., Kyriacou., C. \& Tsorakis, S. (2013). Design and Implementation of a Pedagogical Framework for the Introduction of Distance Learning Programs at Frederick University. Proceedings of the International Conference in Open and Distance Learning (ICODL 2013), Athens, Greece, November 10-13, 2013.

Garrison, D. R., Anderson, T. \& Archer, W. (2000). Critical inquiry in a text-based environment: Computer conferencing in higher education. The Internet and Higher Education, 2 (2-3), 87-105.

Garrison, D.R. \& Arbaugh, J.B. (2007). Researching the community of inquiry framework:

Review, issues, and future directions. Internet and Higher Education, 10 (3), 157-172.

Hewitt, J. S. M. 1998. Design Principles for the Support of Distributed Processes, Educational Psychology Review, Vol.10, No. 1,pp 75-96.

Makrakis, V. \& Costoulas-Makrakis, N. (2012). Course curricula design and development of the M.Sc. programme in the field of ICT in education for sustainable development. Journal of Teacher Education for Sustainability, 14 (2), 5-40.

Martin, F., Budhrani, K., Kumar, S., \& Ritzhaupt, A. (2019). Award-winning faculty online teaching practices: Roles and competencies. Online Learning, 23(1), 184-205. doi:10.24059/olj.v23i1.1329

Salmon, G. (2000). E-Moderating: The Key to Teaching and Learning Online (1st ed.). London: Kogan Page.

Salmon, G. (2004). E-Moderating: The Key to Teaching and Learning Online (2nd ed.). London: Taylor \& Francis.

Shea, P. \& Bidjerano, T. (2010). Learning presence: Towards a theory of self-efficacy, self-regulation and the development of a communities of inquiry in blended and online learning environments. Computers \& Education, 55 (4) 1721-1731.

Stephenson, J. (2001). Teaching and learning online: Pedagogies for new technologies. London: Kogan Page.

Tianguang Gao and James D. Lehman, (2003). The effects of different levels of interaction on the achievement and motivational perceptions of college students in a web-based learning environment. Journal of Interactive Learning Research, 14 (4), 367-387.

Watts, N. (2010). Reflecting on Models for Online Learning in Theory and Practice. The All Ireland Journal of Teaching and Learning in Higher Education, 2 (1), 1-12. Retrieved from http://ojs.aishe.org/index.php/aishe-j/article/view/19

\section{Appendix}


$10^{\text {th }}$ International Conference in Open \& Distance Learning - November 2019, Athens, Greece - PROCEEDINGS

\begin{tabular}{|c|c|c|c|}
\hline Schools & Programs of Studies & Courses & Instructors \\
\hline \multirow{5}{*}{$\begin{array}{c}\text { School of } \\
\text { Business and Law }\end{array}$} & BA in Business Administration & 6 & 5 \\
\hline & $\begin{array}{c}\text { MA-MLL in Maritime Law and Shipping } \\
\text { Management }\end{array}$ & 7 & 5 \\
\hline & Master in Business Administration (Greek) & 3 & 6 \\
\hline & Master in Business Administration (English) & 25 & 13 \\
\hline & $\begin{array}{c}\text { MSc in International Trade and Shipping } \\
\text { Management }\end{array}$ & 6 & 4 \\
\hline $\begin{array}{l}\text { School of Health } \\
\text { Sciences }\end{array}$ & MSc in Health Management & 2 & 3 \\
\hline \multirow{4}{*}{$\begin{array}{l}\text { School of } \\
\text { Education and } \\
\text { Social Sciences }\end{array}$} & MA in Educational Administration & 32 & 31 \\
\hline & M.Ed in Adult Education & 6 & 6 \\
\hline & M.Ed in Special Education & 9 & 11 \\
\hline & MSc in Curriculum and Instruction & 4 & 6 \\
\hline & Overal & 100 & 90 \\
\hline
\end{tabular}

Table 1: DL Programs Evaluated

Table 2: Minor and Major Deviations

\begin{tabular}{|l|l|}
\hline \multicolumn{2}{|c|}{ MEVIATIONS } \\
\hline \multicolumn{2}{|c|}{ Minor Deviations } \\
\hline Welcoming message & \multicolumn{1}{c|}{ Major Deviations } \\
\hline Discussion forum & Interactive activities \\
\hline Course outline & Assessment activities \\
\hline Title & Tele-conferencing sessions \\
\hline Dates & \\
\hline Weekly objectives and topics & \\
\hline Study resources & \\
\hline Digital book(s) /e-book(s) & \\
\hline Exams revision & \\
\hline Weekly structure & \\
\hline
\end{tabular}

